\title{
Rawls, Habermas e a revisão de cláusulas pétreas ${ }^{1}$
}

\author{
Paulo José Machado Corrêa²
}

\section{Resumo}

O presente artigo pretende relacionar o pensamento de John Rawls e Jürgen Habermas com a possibilidade de modificação das cláusulas pétreas. Examinar tal possibilidade pode contribuir para aprofundar o debate teórico e pragmático sobre a função que tais cláusulas exercem como garantia da Constituição, evitando sua dissociação da realidade e sua própria superação revolucionária. O pensamento dos referidos autores parece não se afastar dessa possibilidade, sendo possível encontrar alguns indícios de que a teoria de ambos agasalha um amplo espaço para o desenvolvimento de práticas democráticas, que possam assegurar a preservação da Constituição, ainda que ocorra, eventualmente, a revisão de cláusulas pétreas.

Palavras-chave: Revisão. Cláusulas pétreas. Possibilidade de modificação.

\section{Introdução}

Os limites materiais ao poder de reforma constitucional caracterizam-se como um tema que assume especial relevo no direito constitucional brasileiro, em virtude da natureza analítica da Constituição Federal de 1988, que estabeleceu um extenso rol de cláusulas pétreas em seu texto. Tal característica pode eventualmente potencializar os efeitos de uma crise institucional, se não for possível oferecer alternativas jurídico-políticas que permitam a discussão das cláusulas pétreas e, assim, impeçam a ruptura da ordem constitucional.

1 Artigo está cadastrado no Digital Object Identifier System sob o número doi:10.5102/ prismas.2010.07.1.04 Disponível em: <www.publicaçõesacadêmicas.uniceub.br>.

2 Mestrando em Direito e Políticas Públicas pelo Centro Universitário de Brasília - UniCEUB. Professor de Direito Processual Civil pelo UniCEUB. Procurador do Distrito Federal e advogado 
Nesse contexto, o presente artigo tem por objeto a análise da possibilidade de alteração das chamadas cláusulas pétreas, levando em consideração as contribuições de John Rawls e Jürgen Habermas para a discussão da justiça.

Assim, pretende-se examinar mais detidamente a problemática envolvendo as cláusulas pétreas como técnica de garantia do texto constitucional, em confronto com a possibilidade constitucional de revisão de tais cláusulas constitucionais, sem que para isso seja necessário convocar uma nova Assembléia Constituinte ou provocar uma revolução, cotejando tal possibilidade com o pensamento dos referidos autores.

Ainda que Rawls e Habermas em suas vastas contribuições teóricas sobre a organização da sociedade por meio do direito não tratem especificamente da possibilidade de modificação das cláusulas pétreas, pode ser proveitoso examinar o pensamento desses dois autores, para tentar encontrar alguns pontos de apoio sobre os quais seria lícito examinar tal possibilidade.

Com efeito, como observa Oscar Vilhena Vieira, "formulações na esfera da teoria política como as de Habermas e Rawls possibilitam pensar uma teoria das cláusulas superconstitucionais que seja mais consistente que as derivadas do direito natural, do direito positivo ou da teoria do poder constituinte" ${ }^{3}$. Isso porque, apesar de a questão dos limites materiais ser uma questão jurídica, de direito positivo, ela se coloca também como uma questão política a exigir atenção da teoria política para um tratamento adequado do problema.

\section{Justificativa}

A análise e a formulação de alternativas teóricas e dogmáticas para a realização do projeto do constitucionalismo exige que os intérpretes do texto constitucional consigam proporcionar a máxima efetividade das suas disposições, procurando identificar e impedir que as eventuais tensões em relação ao conteúdo da Constituição ameacem a estabilidade das instituições democráticas, as quais em um Estado Constitucional devem se conformar de acordo com os comandos normativos da Carta Política.

3 VIEIRA, Oscar Vilhena. A Constituição e sua reserva de justiça: um ensaio sobre os limites materiais ao poder de reforma. São Paulo: Malheiros, 1999. p. 230. 
O assunto adquire especial significado, sobretudo em face da Constituição brasileira, que possui um extenso rol de cláusulas pétreas, suscitando, por conseguinte, vários problemas práticos associados ao tema. Em especial, os direitos fundamentais consagrados na Carta de 1988 e dotados da garantia de imutabilidade podem ser objeto de tal investigação, já que a possibilidade de flexibilização atingiria tal categoria de direitos diretamente.

$\mathrm{Na}$ doutrina, encontram-se algumas manifestações que denotam a importância e dificuldade do assunto. Jorge Miranda, por exemplo, observa que "o sentido a conferir aos limites materiais da revisão constitucional tem sido uma vexata questio que há cerca de cem anos divide os constitucionalistas"'. A atualidade do tema, por sua vez, pode ser sentida pela precisa observação de Gilmar Ferreira Mendes a respeito do problema:

Tem sido intensa a discussão, entre nós, sobre a aplicação das chamadas cláusulas pétreas. Muitos afirmam que determinado princípio ou disposição não pode ser alterado sem afronta às cláusulas pétreas. Outros sustentam que determinada proposta afrontaria uma decisão fundamental do constituinte e não poderia, por isso, ser admitida ${ }^{5}$.

Sabe-se que a consagração de cláusulas pétreas em um texto constitucional serve para limitar a atividade do legislador constituinte derivado, que não poderá alterar determinados núcleos jurídicos instituídos pelo legislador constituinte originário. Pretende-se, desse modo, proteger o texto constitucional contra alterações em seus aspectos essenciais.

No entanto, pode-se questionar se uma concepção muito rígida das cláusulas pétreas não poderia levar a impasses um dado ordenamento jurídico, resultando eventualmente até mesmo na ruptura da ordem constitucional, já que somente mediante a atuação do poder constituinte originário, que por definição é ilimitado, seria possível alterar as decisões políticas cunhadas com a garantia da imutabilidade no texto da constituição.

4 MIRANDA, Jorge. Manual de direito constitucional. 3. ed. Coimbra: Coimbra Editora, 1991. p. 190. Tomo II.

5 MENDES, Gilmar Ferreira. Limites da revisão: cláusulas pétreas ou garantias de eternidade - possibilidade jurídica de sua suparação. Ajuris, Rio Grande do Sul, n. 60, p. 249, mar. 1994. 
Com efeito, vários são os problemas teóricos e práticos, políticos e jurídicos que se colocam com relação às cláusulas pétreas. O comprometimento das gerações futuras pelas opções políticas realizadas pelas gerações passadas é um problema delicado, não apenas para a estabilidade constitucional do Estado, mas também quanto à sua legitimidade democrática.

Para exemplificar a delicadeza da questão, basta cogitar-se de um assunto que periodicamente vem à tona: a pena de morte. Sempre que um crime bárbaro é cometido, surgem opiniões no sentido de que a pena de morte deveria ser instituída no Brasil. Por vezes, chega-se inclusive à coleta de assinaturas para que a questão seja discutida no Congresso Nacional. Independentemente da opinião que se tenha sobre a pena de morte, parece razoável permitir que a questão seja debatida e que haja a possibilidade, se assim entender em determinado momento a sociedade, que a pena de morte possa vir a ser disciplinada constitucionalmente. No atual cenário, a única possibilidade seria uma revolução que culminasse com a instalação do poder constituinte originário, para a feitura de uma nova Constituição. Isso, contudo, não parece conveniente.

O mesmo exemplo vale para a instituição da pena de prisão perpétua, que não é admitida em nenhuma hipótese, em uma disciplina ainda mais fechada que a da própria pena de morte. De acordo com o entendimento tradicional, a pena de prisão perpétua não poderia ser introduzida na ordem jurídica brasileira, a não ser se houvesse uma revolução com a elaboração de todo um novo texto constitucional originário ${ }^{6}$.

${ }^{6}$ Os exemplos podem se multiplicar à vontade: nos termos do art. $5^{\circ}$, XII, o sigilo da correspondência e das comunicações telegráficas e de dados é inviolável, não admitindo o texto constitucional sequer restrição mediante lei. Se em determinado momento, para o combate à criminalidade, se verificasse a necessidade de limitação do sigilo nesses casos, qual seria a alternativa? Em face da garantia do art. $5^{\circ}, \mathrm{XXXV}$, seria possível a adoção de um contencioso administrativo no Brasil, ainda que em determinado momento isso se revelasse recomendável? A extinção do júri popular seria possível constitucionalmente? Seria possível alterar o inciso LVII, do art. $5^{\circ}$, para o fim de considerar que enquanto não houve o trânsito em julgado ninguém poderá ser definitivamente considerado culpado, mas provisoriamente sim? Seria impossível a introdução de alguma nova hipótese de prisão civil, ainda que no futuro fossem identificadas circunstâncias de fato que a recomendassem? Esses são apenas alguns exemplos, elaborados sem maior profundidade, tão-somente para ilustrar a complexidade do tema. Bastante interessante revela-se o 
No mundo contemporâneo, o problema agrava-se ainda mais, pois o avanço científico e tecnológico experimentado nas últimas décadas, especialmente com a difusão cada vez mais rápida das informações, implica mudanças cada vez mais frequentes em todas as áreas da vida humana e social, exigindo uma grande capacidade de adaptação por parte das estruturas normativas e burocráticas, sob pena de o ordenamento jurídico tornarse anacrônico, obsoleto e incapaz de enfrentar os desafios resultantes da mudança das relações familiares, sociais, culturais, econômicas, trabalhistas, previdenciárias, dentre outras, assim como incapaz de fazer face aos desafios da globalização ${ }^{7}$.

Por isso mesmo, deve-se refletir se a alteração do texto constitucional não deveria ser vista como algo natural na vida das constituições. Como bem observa Paulo Bonavides:

[...] a imutabilidade constitucional, tese absurda, colide com a vida, que é mudança, movimento, renovação, progresso, rotatividade. Adotá-la equivaleria a cerrar todos os caminhos à reforma pacífica do sistema político, entregando à revolução e ao golpe de Estado a solução das crises. A força e a violência, tomadas assim por árbitro

exemplo dado por Bruce Ackerman quanto à questão da liberdade religiosa. Ainda que nos Estados Unidos tal direito não seja tratado como cláusula pétrea, já que a única disposição imodificável da Constituição americana diz respeito à paridade de representação dos Estados no Senado, o exemplo de Ackerman adequa-se perfeitamente à realidade brasileira. Assim formula ele seu caso hipotético: "suponhamos que o renascimento religioso, atualmente proeminente no mundo islâmico, pudesse constituir a primeira onda de um grande despertar que envolvesse o Ocidente cristão. Uma rejeição generalizada contra o materialismo pagão mobilizando políticas de massa e que resultasse finalmente em um projeto de alteração parcial da Primeira Emenda Constitucional. Com o renascer do novo milênio, a Emenda XXVII seria proclamada por todo o território nacional com a seguinte redação: $\mathrm{O}$ cristianismo é a religião nacional do povo estadunidense e os cultos públicos a outros deuses, de qualquer natureza, são proibidos nos termos desta Emenda" ACKERMAN, Bruce. Nós, o povo soberano: fundamentos do direito constitucional. Trad. Mauro Raposo de Mello. Belo Horizonte: Del Rey, 2006. p. 17-18.

7 Sobre o tema vide: ARNAUD, André-Jean. O direito entre modernidade e globalização: lições de filosofia do direito e do Estado. Trad. Patrice Charles Wuillaume. Rio de Janeiro: Renovar, 1999. Manoel Gonçalves Ferreira Filho destaca a textura aberta das constituições contemporâneas, que correspondem à "necessidade de uma flexibilização dos imperativos constitucionais em face da realidade sempre cambiante. Mais, em velocíssima transformação, numa época de 'globalização"' FERREIRA FILHO, Manoel Gonçalves. Curso de direito constitucional. 34. ed. São Paulo: Saraiva, 2008. p. 391. 
das refregas constitucionais, fariam cedo o descrédito da lei fundamental ${ }^{8}$.

Assim, também a alteração eventual das cláusulas pétreas, de acordo com um procedimento especial e criterioso, poderia vir a ser uma alternativa para permitir a mudança natural do texto, sem ruptura da ordem constitucional vigente. Nesse sentido, alguns autores têm procurado demonstrar que as cláusulas pétreas são passíveis de modificação, embora para isso exija-se um processo mais complexo.

Jorge Miranda defende a tese da dupla revisão ou do duplo processo de revisão, a partir da compreensão de que os limites materiais à revisão das normas constitucionais são logicamente necessários e devem ser protegidos, mas que as disposições específicas do sistema constitucional que consagram tais limites podem ser removidas ou alteradas em um dado contexto histórico 9 .

De acordo com o mecanismo proposto pelo citado autor, seria possível ao legislador constituinte derivado retirar do elenco de cláusulas pétreas a norma que pretende ver reformada, de modo que posteriormente, mediante outra emenda constitucional, alterasse a norma não mais sujeita à imutabilidade.

Também Biscaretti di Ruffia sustenta a possibilidade de revisão dos limites previstos no texto constitucional para a sua reforma. Após proceder à diferenciação entre limites implícitos e limites explícitos, o autor cita o exemplo italiano quanto ao limite explícito do art. 139 da Constituição italiana, segundo o qual "a forma republicana não pode ser objeto de reforma constitucional". Segundo ele.

[...] parece que a solução mais correta (ainda que fortemente afastada, sobretudo, por motivos políticos) seja exigir a ab-rogação preventiva do mesmo artigo que tem, evidentemente, a mesma eficácia de todos os demais artigos da Constituição, depois do que se poderia propor reformas constitucionais mesmo contrastantes com seu conteúdo.

Elimina-se, assim, a tese radical de que toda modificação nesse sentido poderia ser apenas realizada por via antijurídica (por ex.: Balladore-Pallieri, Mortati, o que, por outro lado, implicaria que qualquer propaganda monárquica deveria

8 BONAVIDES, Paulo. Curso de direito constitucional. 7. ed. São Paulo: Malheiros, 1997. p. 173-174.

9 MIRANDA, Jorge. Manual de direito constitucional. 3. ed. Coimbra: Coimbra Editora, 1991. p. 198. Tomo II. 
entrar na hipótese delituosa do art. 283 do Código Penal Italiano (fato dirigido a mudar a Constituição e a forma do governo com meios ilegais), enquanto que, ao contrário, a Lei de 3 de dezembro de 1947, n. 1.546, punia a atividade mencionada apenas se desenvolvida 'com meios violentos.' ${ }^{10}$

No entanto, é importante considerar que o assunto é polêmico, havendo importantes vozes discordantes do mecanismo da dupla revisão. Nesse sentido, Gomes Canotilho afirma que "a tese do duplo processo de revisão, conducente à relatividade dos limites de revisão, parece-nos de afastar”. E fundamenta sua opinião na compreensão de que as normas de revisão são qualificadas como normas superconstitucionais, que atestariam a superioridade do legislador constituinte originário e cuja violação atingiria a própria garantia da Constituição. Assim, “a violação das normas constitucionais que estabelecem a imodificabilidade de outras normas constitucionais deixará de ser um acto constitucional para se situar nos limites de uma ruptura constitucional"."11

Não obstante sua posição contrária à alteração dos limites de revisão, Canotilho não olvida a importante questão a respeito dos limites materiais do poder de revisão, o qual tem estreita ligação com o problema democrático, a saber, a vinculação de gerações futuras a escolhas políticas realizadas por gerações passadas. Assim, se expressa o constitucionalista português a esse respeito, verbis:

O verdadeiro problema levantado pelos limites materiais do poder de revisão é este: será defensável vincular gerações futuras a ideias de legitimação e a projectos políticos que, provavelmente, já não serão os mesmos que pautaram o legislador constituinte? Por outras palavras que se colheram nos Writings de Thomas Jefferson: 'uma geração de homens tem o direito de vincular outra'? A resposta tem de tomar em consideração a evidência de que nenhuma constituição pode conter a vida ou parar o vento com as mãos. Nenhuma lei constitucional evita o ruir dos muros dos processos históricos, e, consequentemente, as alterações constitucionais, se ela já perdeu a sua força normativa. ${ }^{12}$

${ }^{10}$ RUFFİA, Paolo Biscaretti di. Direito constitucional: instituições de direito público. Trad. Maria Helena Diniz. São Paulo: RT, 1984. p. 231.

${ }^{11}$ CANOTILHO, José Joaquim Gomes. Direito constitucional e teoria da constituição. 3. ed. Coimbra: Livraria Almedina, 1999. p. 997.

${ }^{12}$ CANOTILHO, José Joaquim Gomes. Direito constitucional e teoria da constituição. 3. ed. Coimbra: Livraria Almedina, 1999. p. 995. 
Percebe-se que o problema não é tão simples quanto pode parecer a uma primeira análise.

No Brasil, Manoel Gonçalves Ferreira Filho sustenta a tese da modificabilidade das cláusulas pétreas, mediante o mecanismo da dupla revisão. Para o referido autor, seria absurdo que se proibisse a alteração de normas constitucionais de acordo com um processo jurídico, legítimo e democrático, forçando o recurso à revolução para alterá-las. Como bem ressalta, a proibição de modificação de determinadas cláusulas do texto constitucional é apenas um agravamento da rigidez, já que todas as normas constitucionais são dotadas de uma certa rigidez. Assim, "as matérias abrangidas pelas 'cláusulas pétreas' seriam duplamente protegidas. Para modificá-las, seria preciso, primeiro, revogar a 'cláusula pétrea'; depois, segundo, alterar as disposições sobre a matéria em questão"13.

Verificar a possibilidade constitucional de alteração das cláusulas pétreas pode contribuir para aprofundar o debate teórico e pragmático sobre o papel que os limites ao poder de revisão constitucional efetivamente exercem como garantia do texto, e também para evitar que a Constituição fique dissociada da realidade constitucional e acabe por acarretar sua própria superação por meios revolucionários.

Assim, atestada a importância do assunto, bem como a intensa polêmica doutrinária, pretende-se examinar a questão a partir de uma perspectiva específica, qual seja, o papel da constituição na organização da sociedade.

Destarte, nesse contexto, pode ser interessante ver o que Rawls e Habermas têm a dizer sobre o assunto.

\section{0 equilíbrio reflexivo}

Rawls identifica como objeto primário da justiça a chamada estrutura básica da sociedade, que nada mais é senão a forma pela qual as instituições sociais mais importantes irão distribuir os direitos e deveres fundamentais entre os sujeitos que compõem aquela sociedade e determinar a divisão de vantagens provenientes da

${ }^{13}$ FERREIRA FILHO, Manoel Gonçalves. O poder constituinte. 3. ed. São Paulo: Saraiva, 1999. p. 179. 
cooperação social. Para ele, esse arranjo básico da sociedade é também fruto de um contrato social, mas não como compreendido a partir de Locke, Rousseau ou Kant, mas sim em um plano geral e mais abstrato. Serão os princípios da justiça -que pessoas livres e racionais, preocupadas em promover seus próprios interesses, aceitam em uma posição inicial de igualdade - que vão definir os termos fundamentais dessa associação. Assim, o contrato social de Rawls tem um conteúdo principiológico, característica que diferencia seu pensamento daquele dos contratualistas clássicos. As questões que se colocam, então, são as seguintes: como é que se pode fundar uma ordem social justa? Que procedimento poderia ser adotado para a definição desses princípios da justiça?

Rawls parte da ideia de uma posição original de igualdade, formada por sujeitos desinteressados uns em relação aos outros, que agem racionalmente para a realização dos seus próprios interesses. O que caracteriza essa posição original é que os sujeitos que lá se encontram não têm quaisquer informações sobre a sua classe ou status social, convicções religiosas ou políticas, sobre os seus dons naturais, habilidades, características, inteligência, força ou qualquer outro dado que no contexto social possa constituir uma vantagem ou desvantagem para o sujeito. Rawls dá a essa característica da posição original o nome de véu de ignorância. Será sob esse véu de ignorância que os sujeitos que se encontram na posição original escolherão os princípios da justiça, garantindo assim que ninguém possa ser favorecido ou desfavorecido pelas escolhas que fizer. Exemplificativamente, os sujeitos nessa posição original não decidiriam por um regime que promovesse a perseguição de uma raça ou etnia, pois ,ao deixarem a posição original e se situarem na sociedade real, poderia acontecer de a sua posição corresponder à daquela raça ou etnia. Por isso Rawls fala em justiça como equidade, pois, nessa posição inicial, os princípios são escolhidos em uma condição de absoluta equidade ${ }^{14}$. Mediante tal procedimento, os princípios da justiça serão escolhidos pelos sujeitos da posição original.

Explicado o procedimento, em seguida Rawls procura demonstrar os princípios que seriam escolhidos na posição original pelos sujeitos submetidos ao véu da ignorância. Segundo ele, dois princípios poderiam ser identificados: i) cada pessoa deve ter um direito igual ao mais abrangente sistema de liberdades básicas

\footnotetext{
${ }^{14}$ RAWLS, John. Uma teoria da justiça. Trad. Almiro Pisetta e Lenita M. R. Esteves. São Paulo: M. Fontes, 1997. p. 12-14.
} 
iguais que seja compatível com um sistema semelhante de liberdades para as outras; e ii) as desigualdades sociais e econômicas devem ser ordenadas de tal modo que sejam ao mesmo tempo consideradas como vantajosas para todos dentro dos limites do razoável e sejam vinculadas a posições e cargos acessíveis a todos ${ }^{15}$. $\mathrm{O}$ primeiro princípio significa preservar a esfera individual de liberdade, assegurando assim a todos um conjunto de liberdades básicas que lhes permita desenvolver os seus interesses e buscar seu bem no contexto das relações sociais. Já o segundo princípio reconhece a igualdade equitativa de oportunidades, no sentido de que se deve proporcionar a todos a mesma posição para a satisfação de seus interesses e que, por isso mesmo, as desigualdades, sejam naturais, sejam sociais, só podem ser toleradas na medida em que contribuam para melhorar a situação dos menos favorecidos. Vê-se na identificação desses dois princípios a preocupação de Rawls com a identificação de um conteúdo substancial para sua teoria da justiça ${ }^{16}$.

A partir do estabelecimento dos princípios da justiça, Rawls propõe outros três estágios importantes para a aplicação da teoria da justiça, a saber: i) a definição de uma constituição para aquela sociedade, com o detalhamento do sistema de poderes do governo, as formas políticas e os direitos básicos do cidadão; ii) a criação de leis para aplicação dos princípios da justiça e das normas constitucionais; e iii) a aplicação das regras a casos particulares por parte dos juízes, administradores e dos próprios cidadãos em geral nas suas relações sociais. $\mathrm{O}$ que caracteriza essa sequência de quatro estágios é que à medida que se vai avançando na sequência, o véu de ignorância vai sendo retirado e os sujeitos passam a ter conhecimento dos fatos e circunstâncias que caracterizam a vida naquela sociedade.

${ }^{15}$ RAWLS, John. Uma teoria da justiça. Trad. Almiro Pisetta e Lenita M. R. Esteves. São Paulo: M. Fontes, 1997. p. 64.

${ }^{16}$ No mesmo sentido, Oscar Vilhena Vieira observa que "os princípios de justiça, os consensos sobrepostos e os essenciais constitucionais, cada um na sua esfera, não constituem valores transcendentes como os direitos naturais, mas princípios decorrentes da razão humana, voltados à organização da sociedade em que os homens sejam compreendidos como fins, e não como meios. Neste sentido, a teoria da justiça de Rawls não é simplesmente procedimental, pois, na realidade, o procedimento é um meio de realizar ou de assegurar que seres iguais, racionais e autônomos se associem sem que uns se tornem instrumentos de outros" VIEIRA, Oscar Vilhena. A Constituição e sua reserva de justiça: um ensaio sobre os limites materiais ao poder de reforma. São Paulo: Malheiros, 1999. p. 224. 
Assim, percebe-se no modelo de Rawls uma tentativa de, a partir de determinados instrumentos metodológicos, construir-se uma forma de procedimento que assegure a elaboração de princípios de justiça que orientarão a sociedade na busca do justo ${ }^{17}$.

O ponto que se afigura relevante em relação à possibilidade de modificação das clásulas pétreas está associado àquilo que Rawls chama de equilíbrio reflexivo. Para Rawls o equilíbrio reflexivo é um estado em que se alcança a configuração da situação inicial que possa ao mesmo tempo expressar pressuposições razoáveis e produzir princípios que se ajustem às conviç̧ões dos sujeitos, devidamente apuradas e ajustadas. ${ }^{18}$ Como ele próprio afirma, "trata-se de um equilíbrio porque finalmente nossos princípios e opiniões coincidem; e é reflexivo porque sabemos com quais princípios nossos julgamentos se conformam e conhecemos as premissas das quais derivam". ${ }^{19}$

Vale ressaltar - e essa é a questão central - que para Rawls, o equilíbrio reflexivo não é necessariamente estável, estando sujeito "a ser perturbado por outro exame das condições que se pode impor à situação contratual e por casos particulares que podem nos levar a revisar nossos julgamentos". ${ }^{20}$ Obviamente Rawls não se refere aqui à questão das cláusulas pétreas, até porque no seu processo de quatro etapas ele está tratando, nesse contexto, da primeira etapa. Mas justamente por conta disso é que o argumento parece poder ser utilizado com mais intensidade ainda: se Rawls concebe o equilíbrio reflexivo como uma espécie de continuum, que sempre poderia implicar a alteração e a modificação da configuração da situação inicial, com muito mais razão parece razoável supor que seria possível também, observando determinadas formalidades, refletir sobre as clásulas pétreas, que se situam na segunda etapa do processo, ou seja, no nível constitucional e, portanto, naturalmente mais sujeitas a um juízo sobre a sua conveniência e adequação aos anseios da sociedade.

${ }^{17}$ Cf. ABREU, Luiz Eduardo de Lacerda. Qual o sentido de Rawls para nós? Revista de Informação Legislativa, Brasília, n. 172, p. 150, out./dez. 2006.

${ }^{18}$ RAWLS, John. Uma teoria da justiça. Trad. Almiro Pisetta e Lenita M. R. Esteves. São Paulo: M. Fontes, 1997. p. 22-23.

${ }^{19}$ RAWLS, John. Uma teoria da justiça. Trad. Almiro Pisetta e Lenita M. R. Esteves. São Paulo: M. Fontes, 1997. p. 23.

${ }^{20}$ RAWLS, John. Uma teoria da justiça. Trad. Almiro Pisetta e Lenita M. R. Esteves. São Paulo: M. Fontes, 1997. p. 23. 
Parecem reforçar essa compreensão as observações de Luiz Eduardo de Lacerda Abreu acerca do equilíbrio reflexivo. Primeiro, o autor observa que o procedimento do equilíbrio reflexivo tem um caráter circular:

[...] das proposições (sempre provisórias) obtidas na posição original a partir, por exemplo, do teste das concepções filosófico-políticas conhecidas num determinado período histórico vai-se até os juízos nos quais se deposita maior confiança. Seriam os princípios e os juízos compatíveis? O mais provável é que eles não o sejam, e, nesse caso, ou se volta às proposições da posição original, modificando-as se for $\mathrm{o}$ caso; ou se convence de que os juízos devem ser, de alguma forma, alterados ou se faz um pouco dos dois. Mas o processo não pára aí. Dos princípios e intuições assim ajustados voltase aos juízos sobre os quais temos menos confiança (pode-se talvez estabelecer uma ordem entre esses juízos, de forma a tratá-los separadamente). Novamente, é possível ajustá-los aos princípios obtidos anteriormente, modificar os princípios ou fazer algo dos dois ${ }^{21}$.

Em segundo lugar, ele observa que não é objetivo do equilíbrio reflexivo fixar de uma vez por todas quais seriam os princípios da justiça. De acordo com sua análise,

[...] mesmo numa situação hipotética de uma sociedade bem-ordenada (suposição que Rawls utiliza para pensar uma sociedade concreta a partir da posição original, com objetivo de limitar a complexidade da discussão), em que as novas gerações concordassem com os princípios da justiça estabelecidos anteriormente, mesmo nessa condição idealizada, os princípios da justiça deveriam ser percebidos como elaborações provisórias, quer dizer, elaborações que poderiam ser revistas sempre que a mudança das condições sociais assim o exigisse $\mathrm{e}^{22}$.

Assim, não parece desarrazoado supor que o pensamento de Rawls legitima a compreensão de que seria possível a modificação de cláusulas pétreas, observadas determinadas circunstâncias e cautelas. Se isso seria conveniente ou não é outro problema, que só pode ser enfrentado em cada situação concreta, devidamente contextualizada em termos de tempo, modo e lugar.

\footnotetext{
${ }^{21}$ ABREU, Luiz Eduardo de Lacerda. Qual o sentido de Rawls para nós? Revista de Informação Legislativa, Brasília, n. 172, p. 153-154, out./dez. 2006.

${ }^{22}$ ABREU, Luiz Eduardo de Lacerda. Qual o sentido de Rawls para nós? Revista de Informação Legislativa, Brasília, n. 172, p. 154, out./dez. 2006.
} 
Assim, ao contrário da crítica que Habermas faz ao pensamento de Rawls, no sentido de que sua teoria privaria os cidadãos de muitas das percepções que eles teriam que assimilar novamente a cada geração ${ }^{23}$, verifica-se uma razoável abertura no modelo concebido por Rawls, a permitir o processo de contínua reflexão e avaliação acerca dos princípios estabelecidos por uma determinada sociedade.

Aliás, o próprio Rawls, ao se defender da referida crítica de Habermas, observa que a sua sequência de quatro estágios permite justamente que os cidadãos discutam continuamente questões de princípios políticos e de política social, arrematando que "o ideal de uma constituição justa é algo pelo qual sempre se trabalha"24.

\section{A Constituição como projeto}

Em comparação com a elaboração teórica de Rawls, Habermas parece dar ao aspecto procedimental da discussão e definição do justo uma maior relevância, na medida em que a partir da construção da chamada teoria da ação comunicativa, que busca determinar o modo como se pode estabelecer um diálogo ideal, seria possível aos diferentes sujeitos que vivem em sociedade discutir a justiça e chegar à solução para os problemas concretos sobre a sociedade, a partir do reconhecimento dos melhores argumentos. ${ }^{25}$

A partir dessa ideia de ação comunicativa, Habermas preocupa-se com a questão da legitimidade do direito. Para ele são válidas as normas que todos os sujeitos possam aceitar como participantes em um debate público. Assim, só se pode

${ }^{23}$ Cf. HABERMAS, Jürgen. Reconciliation through the public use of reason: remarks on John Rawls political liberalism. The Journal of Philosophy, New York, v. 92, n. 3, p. 128, mar. 1995.

${ }^{24}$ RAWLS, John. Reply to Habermas. The Journal of Philosophy, New York, v. 92, n. 3, p. 154, mar. 1995. Tradução livre. No original: "the ideal of a just constitution is always something to be worked toward".

${ }^{25}$ Rawls observa que "a teoria da ação comunicativa de Habermas produz o esquema analítico da situação de discussão ideal, que oferece uma descrição da verdade e validade dos juízos tanto da razão teórica como da razão prática. Ela busca expor de modo completo os pressupostos da discussão racional e livre, orientada pelas razões mais fortes, de modo que, se todas as condições requeridas forem, de fato, realizadas e plenamente respeitadas por todos os participantes ativos, o seu consenso racional serviria como uma garantia de verdade ou validade. Alternativamente, afirmar que uma delcaração de qualquer tipo é verdadeira, ou que um juízo normativo é válido, é afirmar que ela poderia ser aceita pelos participantes em uma situação de discurso, na medida em que todas as condições requeridas expressas pelo 
falar de legitimidade a partir de um procedimento adequado para que se estabeleça esse debate entre os diferentes sujeitos, cada qual com sua doutrina abrangente. Nesse sentido ele observa que:

[...] na formação discursivamente estruturada da opinião e da vontade de um legislador, há uma ligação entre o processo de elaboração das leis e a formação do poder comunicativo. Podemos esclarecer essa conexão com a ajuda de um modelo processual mais abstrato que inicia com questões pragmáticas, avança para a formação de compromissos e discursos éticos para o esclarecimento de questões morais, e termina com um controle judicial de normas. ${ }^{26}$

A sociedade moderna, caracterizada pelo pluralismo, exige um modelo procedimental que permita aos diferentes atores estabelecer um debate público, que observe as condições ideais do discurso, para alcançar a melhor solução para os problemas da justiça. Na crítica que Habermas faz a Rawls, ele afirma que o modelo rawlsiano acaba por dar primazia aos direitos liberais básicos em detrimento do princípio democrático da legitimação. Isso o impediria de conciliar as liberdades dos modernos (liberdade negativa, ou seja, liberdade de não fazer nada a que não se esteja obrigado) com a liberdade dos antigos (liberdade positiva, ou seja, a liberdade de fazer tudo aquilo que se quer, o exercício da autodeterminação). ${ }^{27}$

ideal valessem" RAWLS, John. Reply to Habermas. The Journal of Philosophy, New York, v. 92, n. 3, p. 139, mar. 1995. Tradução livre. No original: "Haberma's theory of communicative action yields the analytical device of the ideal discourse situation, which offers an account of the truth and validity of judgments of both theoretical and practical reason. It tries to lay out completely the presuppositions of rational and free discussion as guided by the strongest reasons such that, if all requisite conditions were actually realized and fully honored by all active participants, their rational consensus would serve as a warrant for truth or validity. Alternatively, to claim that a statement of whatever kind is true, or a normative judgment valid, is to claim that it could be accepted by participants in a discourse situation to the extent that all the required conditions expressed by the ideal obtained".

${ }^{26}$ HABERMAS, Jürgen. Between facts and norms: contributions to a Discourse Theory of Law and Democracy. Cambridge: The MIT Press, 1996. p. 162. Tradução livre. No original: "In the discursively structured opinion- and will-formation of a legislature, lawmaking is interwoven with the formation of communicative power. We can clarify this connection with the help of a highly abstract process model that starts with pragmatic issues, advances along the branches of compromise formation and ethical discourse to the clarification of moral questions, and ends with a judicial review of norms".

${ }^{27}$ HABERMAS, Jürgen. Reconciliation through the public use of reason: remarks on John Rawls political liberalism, The Journal of Philosophy, New York, v. 92, n. 3, p. 110, mar. 1995. 
Tal compreensão leva Habermas a depositar uma confiança muito grande no aspecto procedimental, como instrumento adequado a viabilizar, em uma sociedade democrática, a discussão da justiça. ${ }^{28}$ Comparando sua proposta com a de Rawls, ele próprio afirma que:

[...] uma tal teoria procedimental moral e legal é ao mesmo tempo mais e menos modesta do que a teoria de Rawls. É mais modesta porque foca exclusivamente os aspectos procedimentais do uso público da razão e deduz o sistema de direitos da idéia de sua institucionalização legal. Isso permite deixar mais questões em aberto porque confia-se mais no processo de opinião racional e formação da vontade. [...] Isso deixa as questões substanciais que devem ser respondidas aqui e agora para o engajamento mais ou menos esclarecido dos participantes, o que não significa que os filósofos não possam também participar do debate público, embora no papel de intelectuais e não de especialistas ${ }^{29}$.

Mas a passagem mais significativa da crítica de Habermas a Rawls é aquela em que ele se refere à Constituição como um projeto, para indicar que os cidadãos devem poder fazer uso público da razão como exercício de autonomia política. Segundo ele, a teoria de Rawls:

[...] priva os cidadãos de muitas das percepções que eles teriam que assimilar novamente a cada geração. Da perspectiva da teoria da justiça, o ato de fundar a constituição democrática não pode ser repetido sob as condições institucionais de uma sociedade justa já constituída, e o

\footnotetext{
${ }^{28}$ Marcelo neves observa que "o modelo habermasiano de Estado Democrático de Direito, não obstante a sua ênfase na fundamentação moral, afirma o caráter legitimador do procedimento democrático: 'O direito não alcança o seu sentido normativo pleno per se, através de sua forma, tampouco mediante um conteúdo moral dado a priori, mas sim através de um procedimento de produção jurídica que gere legitimidade" NEVES, Marcelo. Entre Têmis e Leviatã: uma relação difícil. 2. ed. São Paulo: M. Fontes, 2008. p. 118, grifos do Autor.

${ }^{29}$ HABERMAS, Jürgen. Reconciliation through the public use of reason: remarks on John Rawls political liberalism. The Journal of Philosophy, New York, v. 92, n. 3, mar. 1995, p. 131. Tradução livre. No original: "such a procedural moral and legal theory is at the same time more and less modest than Rawls's theory. It is more modest because it focuses exclusively on the procedural aspects of the public use of reason and derives the system of rights from the idea of its legal institutionalization. It can leave more questions open because it entrusts more to the process of rational opinion and will formation. ... It leaves substantial questions that must be answered here and now to the more or less enlightened engagement of participants, which does not mean that philosophers may not also participate in the public debate, though in the role of intellectuals, not of experts".
} 
processo de realização do sistema de direitos básicos não pode ser garantido em uma base permanente. Não é possível para os cidadãos experimentar esse processo como aberto e incompleto, como as circunstâncias históricas variáveis não obstante exigem. Eles não podem reavivar as brasas democráticas radicais da posição original na vida cívica de sua sociedade, pois de sua perspectiva todos os discursos essenciais de legitimação já tiveram lugar dentro da teoria, e eles encontram os resultados da teoria já sedimentados na constituição. Porque os cidadãos não podem conceber a constituição como um projeto, o uso público da razão não tem realmente o significado de um exercício presente de autonomia política, mas meramente promove a preservação não-violenta da estabilidade política. ${ }^{30}$

Ora, se os cidadãos devem conceber a Constituição como um projeto, parece claro que não pode ela conter uma tal inflexibilidade que impeça a discussão de temas que estão perenizados no texto constitucional, mas que podem não mais corresponder aos anseios e à evolução daquela determinada sociedade.

Tal concepção Habermas já havia sugerido também em sua obra Faktizität und Geltung, de 1992, ao observar que as normas constitucionais não estariam fora do curso da história e imunes às transformações, sendo enganosa a ideia de que as normas são algo estático. Como ele observa nesta passagem:

[...] o caráter das fundações constitucionais, que frequentemente refletem o sucesso das revoluções políticas, enganosamente sugere que normas fora do tempo e resistentes à mudança histórica são simplesmente

\footnotetext{
${ }^{30}$ HABERMAS, Jürgen. Reconciliation through the public use of reason: remarks on John Rawls political liberalism. The Journal of Philosophy, New York, v. 92, n. 3, p. 128, mar. 1995, grifos do Autor. Tradução livre. No original: "deprives the citizens of too many of the insights that they would have to assimilate anew in each generation. From the perspective of the theory of justice, the act of founding the democratic constitution cannot be repeated under the institutional conditions of an already constituted just society, and the process of realizing the system of basic rights cannot be assured on an ongoing basis. It is not possible for the citizens to experience this process as open and incomplete, as the shifting historical circumstances nonetheless demand. They cannot reignite the radical democratic embers of the original position in the civic life of their society, for from their perspective all of the essential discourses of legitimation have already taken place within the theory, and they find the results of the theory already sedimented in the constitution. Because the citizens cannot conceive of the constitution as a project, the public use of reason does not actually have the significance of a present exercise of political autonomy but merely promotes the nonviolent preservation of political stability".
} 
'estatuídas'. A prioridade técnica da constituição em relação às leis faz parte da sistemática de compreensão do estado de direito, mas isso significa apenas que o conteúdo das normas constitucionais é relativamente fixo. Como veremos, toda constituição é um projeto vivo que pode resistir apenas como uma interpretação em andamento, continuamente desenvolvida em todos os níveis de produção do direito. ${ }^{31}$

Parece não distoar, portanto, do sistema concebido por Habermas, a ideia de que, por meio de procedimentos adequados, que garantam o desenvolvimento de um agir comunicativo efetivo entre os cidadãos que compõem a sociedade, seria pelo menos de se admitir, em tese, a discussão sobre a modificação de cláusulas pétreas.

\section{Conclusão}

Pela análise feita, parece correto concluir que, de acordo com o pensamento de Rawls e Habermas seria, em princípio, possível a modificação das cláusulas pétreas. É claro que no contexto da presente análise não se enfrentou o problema de saber se na realidade brasileira tal possibilidade seria conveniente ou não, em razão das várias deficiências de ordem prática com relação ao exercício da democracia, direta ou representativa, no Brasil. Assim, a análise deve ser vista de acordo com o seu propósito: verificar se em tese seria possível a discussão e reformulação daquelas decisões tomadas no passado pelo constituinte originário, protegidas pelas garantias de eternidade.

Vale observar que, não obstante as diferenças entre os modelos de Rawls e Habermas, tanto um como o outro conferem grande relevância ao papel desenvolvido pelos atores sociais na busca da construção de uma sociedade mais justa. As diferenças, como ressalta Thomas McCarthy, derivam das premissas que orientam

${ }^{31}$ HABERMAS, Jürgen. Between facts and norms: contributions to a Discourse theory of Law and democracy. Cambridge: The MIT Press, 1996. p. 129, grifo do Autor. Tradução livre. No original: "the character of constitutional foundings, which often seal the success of political revolutions, deceptively suggests that norms outside of time and resistant to historical change are simply 'stated'. The technical priority of the constitution to ordinary laws belongs to the systematic elucidation of the rule of law, but it only means that the content of constitutional norms is relatively fixed. As we will see, every constitution is a living project that can endure only as an ongoing interpretation continually carried forward at all levels of the production of law". 
Rawls na compreensão do liberalismo e Habermas na compreensão da democracia. Para o referido autor:

Rawls é movido por suas reflexões sobre as origens históricas do liberalismo no contexto das guerras religiosas e das controvérsias sobre tolerância religiosa dos séculos dezesseis e dezessete para propor um modelo atualizado de tolerância para o presente. ... Habermas é movido por suas reflexões sobre as origens históricas da esfera pública democrática nos séculos dezoito e dezenove para propor um modelo atualizado de deliberação para o presente. ${ }^{32}$

Assim, a preocupação maior de Rawls ao preservar a tradição liberal como forma de conciliar diferentes doutrinas abrangentes é justamente assegurar a convivência dos opostos em uma mesma sociedade. E isso, na concepção de Rawls, depende da definição de princípios de justiça que possam estabelecer o mínimo necessário para a cooperação social, mesmo entre opostos.

Por sua vez, Habermas parte para uma análise da democracia como modelo que permite a participação dos diferentes indivíduos que compõem a sociedade e que assim também possibilita a convivência dos opostos. A sua preocupação, portanto, será com a definição de modelos que permitam a implementação da ação comunicativa, de modo a possibilitar que os sujeitos envolvidos no debate público possam fazer uso dos argumentos racionais e buscar a justiça a partir do reconhecimento dos melhores argumentos.

Percebe-se facilmente que a proposta de Habermas confere uma importância muito maior ao aspecto procedimental do que a de Rawls, que se preocupa com a questão substancial, qual seja, definir os princípios da justiça. Para Habermas, o que importa é garantir as condições ideais para que se dê a ação comunicativa, não se preocupando ele em definir previamente um núcleo básico que seria pressuposto para orientar a discussão do justo. Essa preocupação de Rawls, no entender

\footnotetext{
${ }^{32}$ MCCARTHY, Thomas. Kantian Constructivism and Reconstructivism: Rawls and Habermas in Dialogue. Ethics, Chicago, v. 105, n. 1, p. 63, out. 1994. Tradução livre. No original: "Rawls is moved by his reflections on the historical origins of liberalism in the wars of religion and controversies over religious toleration of the sixteenth and seventeenth centuries to propose an updated model of toleration for present purposes ... Habermas is moved by his reflections on the historical origins of the democratic public sphere in the eighteenth and nineteenth centuries to propose an updated model of deliberation for present purposes".
} 
de Habermas, acaba por engessar o processo de criação do justo pela sociedade a cada geração. Daí a crítica de Habermas à teoria de Rawls, já mencionada anteriormente.

Seja como for, o fato é que o pensamento dos dois autores parece não se afastar da possibilidade de permitir a reavaliação das cláusulas pétreas quando isso se apresentar conveniente. Pelo contrário, pode-se encontrar alguns indícios de que a teoria de ambos agasalha um amplo espaço para o desenvolvimento de práticas democráticas, que possam assegurar a manutenção de um determinado texto constitucional, ainda que haja alterações formais ou de mera interpretação das normas constitucionais, mesmo que de cláusulas pétreas, eventualmente.

De fato, não parece haver nenhum motivo suficientemente forte que justifique impedir radicalmente a discussão sobre a modificação de cláusulas pétreas. Independentemente do acerto ou não das previsões constitucionais hoje em vigor (não é isso o que está em jogo aqui), parece razoável permitir que tais questões possam ser objeto de discussão e, eventualmente, modificação pelas instâncias de representação democrática do povo.

Obviamente, as alterações não poderiam ser feitas do mesmo modo que para qualquer outra disposição constitucional, sob pena de se extinguirem as próprias cláusulas pétreas, fazendo desaparecer qualquer diferença entre essas normas constitucionais e todas as demais disposições do texto maior. A princípio, o mecanismo da dupla revisão, proposto por Jorge Miranda e Manoel Gonçalves Ferreira Filho com visto na parte inicial, parece adequado a proporcionar um amplo debate sobre a modificação das cláusulas em questão.

Poder-se-ia pensar também para garantir um maior respaldo popular às modificações que viessem a ser implementadas, em submeter a questão sobre a modificação ou não de tais cláusulas a um plebiscito, somente estando autorizado o Congresso a discutir a questão depois do sinal favorável da sociedade. Ou então, feitas as modificações, submetê-las a referendum, para confirmação ou não da proposta.

Tais mecanismos poderiam inclusive fortalecer a democracia do país, permitindo desenvolver o uso da razão pública, que tanto faz falta hoje ao Brasil e cujo uso, como quer parecer, seria aplaudido por Rawls e Habermas. 


\section{Rawls, Habermas and the revision of immutable rule clauses}

\section{Abstract}

The present article intends to relate the ideas of John Rawls e Jürgen Habermas with the possibility of modification of the immutable rule clauses. Examine such possibility can contribute to improve pragmatic and theoretical debate about the function that such clauses fulfill as guarantee of Constitution, avoiding its dissociation of the reality and its revolutionary overcome. The referred author's ideas don't seem get away from the possibility, being possible to find some signs that both theory includes a wide space to development of democratic practices, that can ensure the preservation of the Constitution, even that occuring, occasionally, the revision of the immutable rule clauses.

Keywords: Revision. Immutable rule clauses. Possibility of modification.

\section{Referências}

ABREU, Luiz Eduardo de Lacerda. Qual o sentido de Rawls para nós? Revista de Informação Legislativa, Brasília, n. 172, p. 149-168, out./dez. 2006.

ACKERMAN, Bruce. Nós, o povo soberano: fundamentos do direito constitucional. Trad. Mauro Raposo de Mello. Belo Horizonte: Del Rey, 2006.

ARNAUD, André-Jean. O direito entre modernidade e globalização: lições de filosofia do direito e do Estado. Trad. Patrice Charles Wuillaume. Rio de Janeiro: Renovar, 1999.

BONAVIDES, Paulo. Curso de direito constitucional. 7. ed. São Paulo: Malheiros, 1997.

CANOTILHO, José Joaquim Gomes. Direito constitucional e teoria da constituição. 3. ed. Coimbra: Livraria Almedina, 1999.

FERREIRA FILHO, Manoel Gonçalves. O poder constituinte. 3. ed. São Paulo: Saraiva, 1999.

FERREIRA FILHO, Manoel Gonçalves. Curso de direito constitucional. 34. ed. São Paulo: Saraiva, 2008. 
HABERMAS, Jürgen. Between facts and norms: contributions to a discourse theory of law and democracy. Cambridge: The MIT Press, 1996.

HABERMAS, Jürgen. Reconciliation through the public use of reason: remarks on John Rawls political liberalism. The Journal of Philosophy, New York, v. 92, n. 3, p. 109-131, mar. 1995.

MCCARTHY, Thomas. Kantian constructivism and reconstructivism: Rawls and Habermas in dialogue. Ethics, Chicago, v. 105, n. 1, p. 44-63, out. 1994.

MENDES, Gilmar Ferreira. Limites da revisão: cláusulas pétreas ou garantias de eternidade - possibilidade jurídica de sua suparação. AJURIS, Rio Grande do Sul, n. 60, p. 249-254, mar. 1994.

MIRANDA, Jorge. Manual de direito constitucional. 3. ed. Coimbra: Coimbra Editora, 1991. Tomo II.

NEVES, Marcelo. Entre Têmis e Leviatã: uma relação difícil. 2. ed. São Paulo: M. Fontes, 2008.

RAWLS, John. Reply to Habermas. The Journal of Philosophy, New York, v. 92, n. 3, p. 132-180, mar. 1995.

RAWLS, John. Uma teoria da justiça. Trad. Almiro Pisetta e Lenita M. R. Esteves. São Paulo: M. Fontes, 1997.

RUFFİA, Paolo Biscaretti di. Direito constitucional: instituições de direito público. Trad. Maria Helena Diniz. São Paulo: RT, 1984.

SILVA, José Afonso da. Curso de direito constitucional positivo. 19. ed. São Paulo, Malheiros, 2001.

VIEIRA, Oscar Vilhena. A Constituição e sua reserva de justiça: um ensaio sobre os limites materiais ao poder de reforma. São Paulo: Malheiros, 1999. 
